\title{
The association between diet and chronic obstructive pulmonary disease in subjects selected from general practice
}

\author{
L. Watson*, B. Margetts", P. Howarth ${ }^{\star}$, M. Dorward*, R. Thompson\#, P. Little*
}

\begin{abstract}
The association between diet and chronic obstructive pulmonary disease in subjects selected from general practice. L. Watson, B. Margetts, P. Howarth, M. Dorward, R. Thompson, P. Little. C ERS Journals Ltd 2002.

ABSTRACT: It is unclear why some smokers develop chronic obstructive pulmonary disease (COPD) whilst the majority do not. Antioxidants found in food may protect against lung tissue injury, but previous epidemiological studies are inconsistent and do not focus on those most at risk of COPD, namely smokers. This case-controlled study measured the difference in dietary intake between smokers and exsmokers with and without COPD.

Cases were patients $>45$ yrs of age with $>10$ pack-yrs of smoking, a forced expiratory volume in one second (FEV1)/forced vital capacity (FVC) of $\leqslant 70 \%$ and a FEV 1 of $\leqslant \mathbf{8 0} \%$ of predicted. Controls were patients $>\mathbf{4 5}$ yrs of age with $>\mathbf{1 0}$ pack-yrs of smoking, a FEV1/FVC of $>70 \%$ and a FEV1 $>80 \%$ pred. Data were collected using validated questionnaires. Logistic regression analysis for an unmatched case-controlled study was performed.

After controlling for other independent predictors of COPD, those with vegetable intake of $\geqslant 1$ portion $\cdot d_{a y}^{-1}(93 \mathrm{~g})$ were less likely to have COPD, as were those consuming $\geqslant 1.5$ portions $\cdot$ day $^{-1}$ of fruit. This was not due to an overall reduction in food/calorie intake caused by the disease because: 1) adjusting for body mass index did not alter the estimates; 2) the effect was specific to fruit and vegetables, i.e. not other food groups; and 3) the estimates from incident cases were similar.

In conclusion, fruit and vegetable consumption is inversely associated with chronic obstructive pulmonary disease and may explain why some smokers do not develop chronic obstructive pulmonary disease.

Eur Respir J 2002; 20: 313-318.
\end{abstract}

*Primary Medical Care Dept, University of Southampton, Aldermoor Health Centre, ${ }^{\#}$ Public Health Nutrition, Institute of Human Nutrition and Medical Specialities, University of Southampton, Southampton General Hospital, Southampton, UK.

Correspondence: P. Little, Primary Medical Care Dept, University of Southampton, Aldermoor Health Centre, Aldermoor Close, Southampton, SO16 5ST, UK.

Fax: 4431503633082

E-mail: ps13@soton.ac.uk

Keywords: Antioxidants, chronic obstructive pulmonary disease, diet, smoking

Received: June 272001

Accepted after revision: March 262002

This study was funded by a Scientific Foundation Award to L. Watson from the Royal College of General Practitioners and a grant from AstraZeneca, Lund, Sweden.
Current concepts about the risk factors associated with chronic obstructive pulmonary disease (COPD) suggest that whilst cigarette smoking may be the principle cause $[1,2]$, other factors may also be important. The fact that $95 \%$ of those with COPD are smokers but only $20 \%$ of smokers develop COPD [3] has led to alternative theories of why some people appear to be more vulnerable to the effects of cigarette smoke. Several epidemiological studies, based on the hypothesis that antioxidants in food may protect the lungs against oxidant attack from the free radicals found in cigarette smoke, have found positive associations between low dietary intake of fruit and vegetables and decreased lung function in general populations [4-10].

Fish intake has also been studied with regard to both lung function and COPD incidence, but although SHAHAR et al. [11] and SHARP et al. [12] found a correlation, TABAK et al. [5] could not find a protective effect for fish. Alcohol, specifically wine, has also been suggested to have the potential to protect cellular structures against peroxidation [13]. Accordingly, GARSHICK et al. [14] found that in heavy smokers, alcohol combined with smoking protected against a decline in forced expiratory volume in one second (FEV1).

To the current authors' knowledge, no studies to date have compared dietary intake in those diagnosed with COPD (with mild-to-severe obstruction) with those without COPD but at highest risk of developing the disease (namely current or exsmokers with $>10$ pack-yrs of smoking). Studies performed in general populations, assessing diet as a risk factor for COPD, have produced conflicting results $[15,16]$. The evidence to date supports the theory that smokers have an antioxidant imbalance [17] caused by cellular biochemical changes leading to injury to lung parenchyma. Antioxidants contained within foods such as fruit and vegetables may protect against tissue injury and smokers consuming low volumes of these food sources could therefore be at greater risk of developing COPD.

Therefore, the current authors' hypothesise that patients with $>10$ pack-yrs of smoking ( 1 pack-yr being defined as 20 cigarettes $\cdot$ day $^{-1}$ for $1 \mathrm{yr}$ ) who consume low amounts of foods containing antioxidants are at greater risk of developing COPD. This paper reports a case-controlled study to assess 
diet as a risk factor for COPD in subjects with $\geqslant 10$ pack-yrs of smoking from general practices in southern England.

\section{Methods}

\section{Sample size and power calculations}

For $80 \%$ power and $95 \%$ confidence using Nquery (Statisical Solutions Ltd, Cork, Ireland), assuming one third of controls had a high intake of antioxidant rich food that this is protective with an odds ratio (OR) of $0.4,115$ cases and 115 controls were required in an unmatched design. This figure was doubled to allow for $50 \%$ nonresponse. This figure was then inflated by a further $50 \%$ to allow for low uptake up of spirometry testing.

\section{Participants}

Figure 1 explains the recruitment process. Subjects with and without a general practioner's (GP) diagnosis

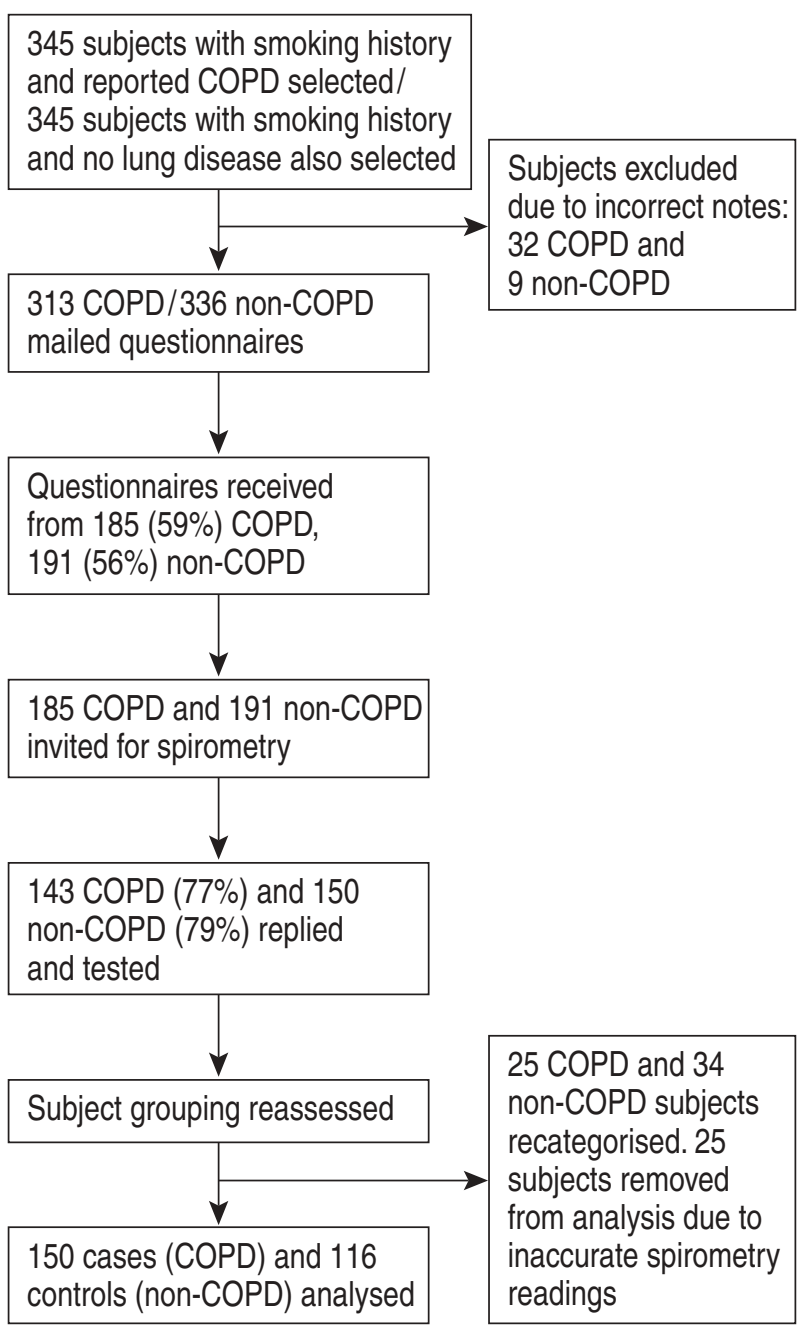

Fig. 1.-Flow diagram of the recruitment process. of COPD, aged $>45$ yrs and with $>10$ pack-yrs of smoking were randomly selected from eight practice lists. Spirometry was used to confirm status as either a case or control using the British Thoracic Society Guidelines [2]. Cases were defined as subjects with an FEV $1 \leqslant 80 \%$ predicted and an FEV1/forced vital capacity (FVC) $\leqslant 70 \%$ pred. Controls were those with an $\mathrm{FEV} 1>80 \%$ pred and an $\mathrm{FEV} 1 / \mathrm{FVC}$ ratio $>70 \%$ pred. Exclusion criteria included all subjects with a history of ischaemic heart disease, diabetes or gastrointestinal disease, where subjects may have been advised to modify their diets. Permission was obtained from the local research ethics committees and subjects gave their informed consent.

\section{Instruments}

After exclusions, the remaining subjects were mailed the HEA3 dietary food frequency questionnaire, validated for use in general practice [18]. This questionnaire asks the frequency (day, week or month) and portion size (small, medium, large) of intake of foods belonging to the six main food groups: fruit and vegetables (including juice), meats and proteins, dairy produce, starchy foods, snack items and fats. Patients were asked to assess their food intake over the proceeding year. The questionnaire, self-administered at home, has proven to be an accurate measure of dietary intake when compared to a 7-day weighed record and does not overestimate intake of food consumption. It is, however, limited to food groups as opposed to including details on individual food items, such as apples, oranges, etc. Therefore, subjects were also asked to complete the EPIC dietary questionnaire [19], which provides more detailed information regarding specific foods but can over estimate consumption. Results presented are from the HEA3 questionnaire unless otherwise stated. These questionnaires allowed ranking of intake of the major food groups and of foods of primary interest, i.e. those containing antioxidants.

Subjects were also sent the American Thoracic Society (ATS) 1978 respiratory questionnaire validated for self-completion at home [20]. This questionnaire measures variables associated with smoking history, symptomatic prevalence and sociodemographical variables, such as employment history, education, and residency. Two reminders were sent to nonresponders.

\section{Spirometry}

M. Dorward performed all spirometric tests to assess FEV1 and FVC, using a hand held Vitalograph 2120 spirometer (Vitalograph, Maids Moreton, UK). All subjects were asked to refrain from taking any inhaled or oral respiratory medication for 4-12 h prior to the test. Each subject was asked to perform three forced expiratory manoeuvres and the maximum value of FEV1 and FVC recorded was used in these analyses. Subjects had their standing height measured using a portable stadiometer and were weighed on 
Table 1.-Characteristics of participants by group

\begin{tabular}{lcc}
\hline & Case & Control \\
\hline Subjects n (\% males) & $150(68)$ & $116(56)$ \\
Age yrs & $71(9)$ & $63(9)$ \\
BMI kg.m & $26.0(4.2)$ & $28.0(4.3)$ \\
FEV1 \% pred & $54.4(18.3)$ & $95.8(17.4)$ \\
FEV1/FVC ratio \% & $50.4(11.5)$ & $77.1(7.0)$ \\
Pack-yrs (IQ range) & $41(28-56)$ & $35(22-49)$ \\
Current smokers \% & 30.7 & 35.3 \\
\hline
\end{tabular}

Data are presented as mean (SD) unless otherwise stated. Case: smokers and exsmokers with chronic obstructive pulmonary disease (COPD); Control: smokers and exsmokers without COPD. BMI: body mass index; $\%$ pred: $\%$ predicted; FEV1: forced expiratory volume in one second; PVC: forced vital capacity; IQ: interquartile.

portable calibrated scales. Patients whose FEV1/FVC were $<70 \%$ and FEV1 was $<80 \%$ and who had symptoms associated with COPD according to the ATS 1978 questionnaire [20], such as cough and phlegm, but who were not originally recorded as having COPD by their GP, were recategorised as COPD patients for the purpose of analysis. It was thought that these patients were likely to have COPD but had failed to attend their GP for diagnosis. Thirtyfour such incident cases were found.

\section{Statistical analysis}

Food variables were divided into equal thirds and then multiple stepwise logistic regression analysis for an unmatched case-controlled study was performed comparing each category with the reference category, i.e. the lowest third of intake. The model was adjusted for body mass index (BMI); some cases of COPD lose body weight due to lower calorie intake, and thus controlling for BMI controlled for the effect of COPD on total calorie intake. Known risk factors for COPD, such as sex, age and social class, were also tested in the model and retained if significance was at 5\%.

\section{Results}

As shown in figure 1, from the initial subjects selected 185 GP-listed COPD subjects $(59 \%)$ and 191 non-COPD-listed subjects $(56 \%)$ replied. Of these, 143 COPD-listed subjects $(77 \%)$ and 150 non-COPDlisted subjects $(79 \%)$ attended a general practice for spirometry. Using the spirometry values, as explained previously, and after recategorising and removing subjects who failed to perform an adequate spirometry test, 150 cases and 116 controls were used for the final analysis. Sex and age comparisons of responders and nonresponders indicated that nonresponders were of similar ages to responders (nonresponder cases 68.6 yrs (SD 11.0), nonresponder controls 61.9 yrs (SD 9.2), with slightly less responding males (nonresponder cases 54\%, nonresponder controls $50 \%$ ), see table 1 for comparison.

The characteristics of cases and controls are summarised in table 1. The risk factors for COPD are summarised in tables 2 and 3. As expected, it was found that the older the subject the greater the risk of COPD $(\mathrm{p}<0.001)$. Also, as expected, having a BMI of $<25$ was also significantly associated with COPD $(\mathrm{p}<0.001)$. After controlling for age and BMI, vegetables were significantly associated with a reduction in the risk of COPD. Benefits from fruit appeared to be mainly in the upper third of subjects who consumed $>121 \mathrm{~g}$ of fruit $\cdot \mathrm{day}^{-1}(\sim 1-2$ portions) compared

Table 2. - Sociodemographical and physiological predictors of chronic obstructive pulmonary disease

\begin{tabular}{|c|c|c|c|c|c|}
\hline Variable & Case & Control & $\begin{array}{l}\text { Unadjusted } \\
\text { OR }(95 \% \text { CI })\end{array}$ & $\begin{array}{l}\text { Adjusted }^{\#} \\
\text { OR }(95 \% \text { CI) }\end{array}$ & $\begin{array}{l}\text { p-value for } \\
\text { adjusted OR }\end{array}$ \\
\hline \multicolumn{6}{|l|}{ Sex } \\
\hline Female & $48(32.0)$ & $50(44.0)$ & 1 & 1 & \multirow[t]{2}{*}{0.59} \\
\hline Male & $102(68.0)$ & $66(56.0)$ & $1.56(0.94,2.59)$ & $1.18(0.64,2.17)$ & \\
\hline \multicolumn{6}{|l|}{ Age yrs } \\
\hline $44-60$ & $18(12.0)$ & $50(43.1)$ & 1 & 1 & \multirow{4}{*}{$<0.001$} \\
\hline $61-70$ & $51(34.0)$ & $45(38.8)$ & $3.02(1.54,5.93)$ & $3.68(1.76,7.73)$ & \\
\hline $71-80$ & $66(44.0)$ & $18(15.5)$ & $10.03(4.74,21.24)$ & $13.39(5.92,30.29)$ & \\
\hline$>80$ & $15(10.0)$ & $3(2.6)$ & $13.89(3.59,53.65)$ & $13.98(3.39,57.70)$ & \\
\hline \multicolumn{6}{|l|}{ Smoking } \\
\hline $10-30$ pack-yrs & $47(31.3)$ & $50(43.1)$ & 1 & 1 & \multirow[t]{3}{*}{0.30} \\
\hline 31-50 pack-yrs & $55(36.7)$ & $38(32.8)$ & $1.61(0.90,2.88)$ & $1.73(0.86,3.45)$ & \\
\hline$>50$ pack-yrs & $48(32.0)$ & $28(24.1)$ & $1.90(1.02,3.54)$ & $1.29(0.62,2.72)$ & \\
\hline \multicolumn{6}{|l|}{ Body mass index } \\
\hline Overweight (>25) & $83(55.3)$ & $90(77.6)$ & 1 & 1 & \multirow{3}{*}{0.001} \\
\hline Normal weight $(20-25)$ & $49(32.7)$ & $21(18.1)$ & $2.53(1.40,4.57)$ & $3.26(1.62,6.54)$ & \\
\hline Underweight $(<20)$ & $12(8.0)$ & $4(3.4)$ & $3.25(1.01,10.48)$ & $3.26(0.88,12.01)$ & \\
\hline \multicolumn{6}{|l|}{ Social class } \\
\hline Nonmanual & $74(49.3)$ & $69(59.5)$ & 1 & 1 & \multirow[t]{2}{*}{0.12} \\
\hline Manual & $56(37.3)$ & $38(32.8)$ & $1.37(0.81,2.33)$ & $1.65(0.87,3.13)$ & \\
\hline
\end{tabular}

Data are presented as n (\%) unless otherwise stated. OR: odds ratio; CI: confidence interval. \#: adjusted for vegetable intake, age and body mass index. 
Table 3. - Dietary predictors of chronic obstructive pulmonary disease

\begin{tabular}{|c|c|c|c|c|c|}
\hline Variable & Case & Control & $\begin{array}{c}\text { Unadjusted } \\
\text { OR }(95 \% \mathrm{CI})\end{array}$ & $\begin{array}{c}\text { Adjusted }^{\#} \\
\text { OR }(95 \% \text { CI })\end{array}$ & $\begin{array}{l}\mathrm{p} \text {-value for } \\
\text { adjusted odds }\end{array}$ \\
\hline \multicolumn{6}{|l|}{ Fruit } \\
\hline $0-22 \mathrm{~g}$ & $57(38.0)$ & $37(31.9)$ & 1 & 1 & \multirow[t]{3}{*}{0.12} \\
\hline $23-120 \mathrm{~g}$ & $76(50.7)$ & $49(42.2)$ & $1.00(0.58,1.74)$ & $0.97(0.50,1.85)$ & \\
\hline $121 \mathrm{~g}$ & 17 (11.3) & $30(25.9)$ & $0.36(0.17,0.75)$ & $0.45(0.19,1.06)$ & \\
\hline \multicolumn{6}{|l|}{ Vegetables } \\
\hline $0-49 \mathrm{~g}$ & $57(38.0)$ & $31(26.7)$ & 1 & 1 & \multirow[t]{3}{*}{$0.02^{+}$} \\
\hline $50-92 \mathrm{~g}$ & $51(34.0)$ & 37 (31.9) & $0.76(0.41,1.40)$ & $0.74(0.36,1.51)$ & \\
\hline $93 \mathrm{~g}$ & $40(26.7)$ & 48 (41.4) & $0.46(0.25,0.85)$ & $0.46(0.23,0.94)$ & \\
\hline \multicolumn{6}{|l|}{ Dairy } \\
\hline $0-203 \mathrm{~g}$ & $53(35.3)$ & $33(28.4)$ & 1 & 1 & \multirow{3}{*}{0.13} \\
\hline $204-288 \mathrm{~g}$ & $44(29.3)$ & 48 (41.4) & $0.57(0.31,1.03)$ & $0.57(0.28,1.15)$ & \\
\hline $289 \mathrm{~g}$ & $50(33.3)$ & $35(30.2)$ & $0.88(0.48,1.64)$ & $1.12(0.53,2.35)$ & \\
\hline \multicolumn{6}{|l|}{ Starch } \\
\hline $0-191 \mathrm{~g}$ & $46(30.7)$ & $36(31.0)$ & 1 & 1 & \multirow{3}{*}{0.48} \\
\hline $192-283 \mathrm{~g}$ & $50(33.3)$ & $35(30.2)$ & $1.11(0.60,2.06)$ & $1.50(0.72,3.15)$ & \\
\hline $284 \mathrm{~g}$ & $51(34.0)$ & $45(38.8)$ & $0.88(0.49,1.60)$ & $1.48(0.70,3.10)$ & \\
\hline \multicolumn{6}{|l|}{ Alcohol ${ }^{\top}$} \\
\hline 0 units & $53(35.3)$ & $27(23.3)$ & 1 & 1 & \multirow[t]{3}{*}{0.33} \\
\hline $1-5$ units $\cdot$ week $^{-1}$ & $61(40.7)$ & $58(50.0)$ & $0.53(0.29,0.96)$ & $0.62(0.31,1.26)$ & \\
\hline 1 unit $^{- \text {day }^{-1}}$ & $33(22.0)$ & $31(26.7)$ & $0.54(0.27,1.06)$ & $0.59(0.27,1.31)$ & \\
\hline
\end{tabular}

Data are presented as n (\%) unless otherwise stated. OR: odds ratio; CI: confidence interval. * : adjusted for vegetable intake, age and body mass index; ": wines, beer, spirits, liqueurs; ${ }^{+}$: test for trend only shown for vegetables.

to the other two groups. When compared to the other two groups combined, this top third were less likely to have COPD (odds ratio (OR) $0.46,95 \%$ confidence interval (CI) $0.21-0.96, \mathrm{p}=0.04)$ when the model was adjusted for the other predictors of COPD. Using data from the EPIC questionnaire about specific fruit and vegetable intake, apple intake (top third, $\geqslant 3 \cdot$ week $^{-1}$ ) was the only fruit or vegetable to show a significant protective association in univariate analysis (OR $0.47,95 \%$ CI 0.24-0.95). In either univariate or multivariate analyses, no other food groups containing antioxidants such as fish and dairy produce, proteins, fats or snack items, were significantly protective or harmful, which suggests the effect is specific to fruit and vegetables and is due to the effects of COPD on overall calorie/food intake. To further test for reverse causality, i.e. to check whether current diet is influenced by the presence of disease, a separate analysis was performed. The 34 incident cases, i.e. the recategorised controls who had never been told by a GP that they had a diagnosis of COPD, were an important group since they had not had a chance to change their diet in response to being told they had lung obstruction. This group showed very similar results to prevalent cases, with an OR for the top tertile of fruit intake in univariate analysis of 0.35 (95\% CI 0.10-1.18). For vegetable intake, the three groups, using the bottom third as a reference, had ORs of $1.0,0.78$ (95\% CI $0.33-1.87)$ and $0.47(95 \%$ CI 0.19-1.16), respectively. This indicates that the results cannot be explained by a change in diet following the diagnosis of COPD.

\section{Discussion}

This study shows that low dietary intake of fruit and vegetables is associated with increased prevalence of COPD in subjects with a smoking history of $>10$ pack-yrs. This suggests that other factors, as well as cigarette smoke, are involved in the development of this major disease whose incidence is currently increasing worldwide [21].

There are several potential limitations of this investigation that should be discussed prior to interpretation of the results.

\section{Selection and response bias}

The authors have no reason to believe that important bias due to selection and response occurred. Information collected on nonresponders indicated that although responders were more likely to be male and slightly older, there was no evidence of a differentiated response bias between those with and without COPD. The slightly larger number of male cases doubtless reflects the current male dominance of the disease, due to higher smoking rates among males in the past, although in this analysis, sex did not predict COPD status. Previous literature does not support sex and dietary interactions in association with COPD.

\section{Recall bias}

Recall bias in the completion of dietary questionnaires is a recognised problem when collecting nutritional data [22]. Social desirability may have played a part in the responses of subjects and those foods considered healthy, e.g. fruit, may have been over-reported. However, HEA3 has previously been shown to accurately assess dietary intake of such foods against a 7-day weighed record [18]. Despite any 
possible over-reporting, there is no reason why cases should report diet differently to controls and subjects who had a diagnosis likely to be associated with dietary change, such as ischaemic heart disease or diabetes, were excluded. If the effect observed was due to differentiated social desirability between cases and controls, then a consistent effect would be seen for foods considered less healthy, e.g. dairy products, fats and snacks, which was not the case. Similarly, a differential affect on appetite or overall calorie intake would be expected to affect all food groups. Underreporting of all foods is particularly common in the overweight [22], and weight reduction due to reduced calorie intake is a well-recognised feature of some cases, leading to reduced BMI. However, controlling for BMI did not significantly alter the estimates, i.e. the adjusted and unadjusted estimates were very similar. Finally, the estimates from incident cases for the association between fruit and vegetables and COPD were very similar to the prevalent cases, i.e. not explained by changes in diet subsequent to diagnosis. Therefore, recall bias and changes in diet due to having the disease are unlikely explanations of the results.

\section{Sample size and study design}

The sample size was powered to detect an OR of 0.4 but a lesser protective effect from other dietary components in a large population cannot be ruled out.

Due to the cross-sectional design of this study, exposure to diet has been established retrospectively. Prospective cohorts would be required to confirm these findings.

\section{Risk factors for chronic obstructive pulmonary disease}

This study shows that a dietary intake of vegetables $\left(\geqslant 93 \mathrm{~g} \cdot \mathrm{day}^{-1}\right)$ and fruit $\left(\geqslant 121 \mathrm{~g} \cdot \mathrm{day}^{-1}\right)$ is inversely associated with COPD. To the authors' knowledge, no other study has attempted to measure the differences in diet between subjects with a defined smoking pack history who have developed COPD and subjects with the same exposure to cigarette smoke who have not developed the disease. MiEdema et al. [9] found fruit and vegetables to be protective against incidence of lung obstruction (defined as episodes of symptoms, such as regular coughing and phlegm for 3 months or a diagnosis by a clinical specialist) in a population of both smokers and nonsmokers, although spirometry was not used to ensure correct diagnosis. In the Seven Countries Study, TABAK et al. [5] found fruit and vegetables to be positively related to pulmonary function as well as protecting against mortality from COPD in a random population [7]. However, the instruments used for dietary data collection differed between the participating countries, making accurate estimation of intake difficult. A number of observations made by other groups assessing lung function in relation to fruit intake, all indicate that high fruit intake leads to an increase in FEV1 $[4,6,9,10]$. These results show that consuming apples $\left(\geqslant 3 \cdot\right.$ week $\left.^{-1}\right)$ was inversely associated with COPD in univariate analysis (OR 0.47, 95\% CI $0.240 .95)$, although not in multivariate analysis, which corroborates with the recent findings of BUTLAND et al. [4], which indicated that those who ate $\geqslant 5$

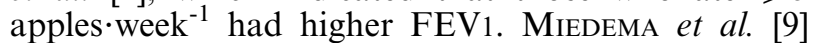
postulated that it could be the antioxidant effect of the flavonoid quercetin, found in high concentrations in apples, onions and red wine, that protects against lung tissue injury. However, red wine and onions did not show any association with COPD in this study. No other individual fruits showed an independent association with COPD, including citrus fruits, which have high levels of vitamin $\mathrm{C}$, previously suggested as a protective antioxidant in association with lung function [23-25]. The findings in this study suggest that it is more likely to be the combined effect of various fruits and vegetables that protect against lung obstruction.

One previous study found that vitamin A from milk was protective against COPD, but this was not seen in this study [15]. Shahar et al. [11] found a protective effect for fish in relation to lung obstruction but this was not confirmed in this study. No other food groups were associated with COPD, so it would appear that fruit and vegetable consumption is the main dietary factor.

\section{Nondietary risk factors for chronic obstructive pulmonary disease}

Age is shown to be a significant risk factor for COPD and is known to be one of the principle risk factors for developing the disease [2]. Subjects $>70 \mathrm{yrs}$ were 13-times more likely to develop COPD in this population of smokers. Pack-yrs of smoking did not remain a significant risk factor when allowing for age and BMI in this model, as both cases and controls were selected based on their cigarette-smoking history and age also contributes considerably to pack years. BMI was significantly associated with COPD. This may be due, in part, to the reduction in calorie intake for some patients with the disease. However, the inverse association between fruit and vegetables and COPD cannot be explained by this since adjusting for BMI did not alter the estimates. Reduced total calorie intake and malnutrition is common in subjects with severe COPD [2] and the lack of significance of the underweight category when compared to the reference group can be explained by the small number of subjects.

Despite antismoking campaigns, many subjects continue to smoke and as they age, greatly increase their risk of developing COPD. If, as it appears here, fruit and vegetables can provide a protective mechanism against the oxidants contained within cigarette smoke, a clear health promotion message would be to encourage all subjects, but particularly smokers, to increase their level of fruit and vegetable intake to at least $\geqslant 1$ portions $\cdot$ day $^{-1}$. However, this hypothesis ultimately needs to be tested in a large-scale intervention study. 


\section{Conclusion}

This study indicates that low vegetable intake is likely to be an important risk factor for chronic obstructive pulmonary disease in subjects with $>10$ pack-yrs of smoking. Higher fruit consumption is also inversely associated with chronic obstructive pulmonary disease. These findings require confirmation in prospective cohorts but suggest that health promotion regarding dietary intake, particularly of fruit and vegetables, should be aimed at those most at risk of developing chronic obstructive pulmonary disease, namely smokers and exsmokers.

Acknowledgements. The authors are grateful to H.A.M. Kerstjens for all his assistance with this study. The authors would like to thank all the staff and patients at the Alton Health Centre (Cubitt Practice), the Webb-Peploe Partnership, Blendworth Lane Surgery, Drayton Surgery, Highlands Road Partnership, Forton Road Surgery, Heyward Road Surgery and Stakes Lodge Surgery.

\section{References}

1. ATS. Standards for the diagnosis and care of patients with chronic obstructive pulmonary disease. Am J Respir Crit Care Med 1995; 152: S77-S120.

2. BTS. BTS guidelines for the management of chronic obstructive pulmonary disease. The COPD Guidelines Group of the Standards of Care Committee of the BTS. Thorax 1997; 52: S1-S28.

3. Madison JM, Irwin RS. Chronic obstructive pulmonary disease. Lancet 1998; 352: 467-473.

4. Butland BK, Fehily AM, Elwood PC. Diet, lung function and lung function decline in a cohort of 2512 aged men. Thorax 2000; 55: 102-108.

5. Tabak C, Smit HA, Rasanen L, et al. Dietary factors and pulmonary function: a cross sectional study in middle aged men from three European countries. Thorax 1999; 54: 1021-1026.

6. Carey IM, Strachan DP, Cook DG. Effect of changes in fresh fruit consumption on ventilatory function in health British adults. Am J Respir Crit Care Med 1998; 158: 728-733.

7. Tabak C, Feskens EJM, Heederick D, Dromhout D, Menotti A, Blackburn H. Fruit and fish consumption: a possible explanation for population differences in COPD mortality (The Seven Countries Study). Eur J Clin Nutr 1998; 52: 819-825.

8. Cook D, Carey I, Whincup P, et al. Effect of fresh fruit consumption on lung function and wheeze in children. Thorax 1997; 52: 628-633.

9. Miedema I, Feskens E, Heederik D, Kromhout D. Dietary determinants of long-term incidence of chronic nonspecific lung diseases. Am $J$ Epidemiol 1993; 138: 37-45.

10. Strachan D, Cox B, Erzinclioglu S, Walters DE, Whichelow M. Ventilatory function and winter fresh fruit consumption in a random sample of British adults. Thorax 1991; 46: 624-629.

11. Shahar E, Folsom AR, Melnick SL, et al. Dietary n-3 polyunsaturated fatty acids and smoking-related chronic obstructive pulmonary disease. $N$ Engl $\mathrm{J} \mathrm{Med}$ 1994; 331: 228-233.

12. Sharp DS, Rodriguez BL, Shahar E, Hwang L, Burchfiel CM. Fish consumption may limit the damage of smoking on the lung. Am J Respir Crit Care Med 1994; 150: 983-987.

13. Durak I, Avci A, Dacmaz M, et al. Comparison of antioxidant potentials of red wine, white wine, grape juice and alcohol. Curr Med Res Opin 1999; 15: 316320.

14. Garshick E, Segal MR, Worobec TG, Salekin CM, Miller MJ. Alcohol consumption and chronic obstructive pulmonary disease. Am Rev Respir Dis 1989; 140: 373-378.

15. Morabia A, Sorenson A, Kumanyika S, Abbey H, Cohen B, Chee E. Vitamin A, cigarette smoking and airway obstruction. Am Rev Respir Dis 1989; 140: 1312-1316.

16. Shahar E, Rolsom A, Melnick S, et al. Does dietary vitamin A protect against airway obstruction. Am J Respir Crit Care Med 1994; 150: 978-982.

17. Rahman I, MacNee W. Oxidant/antioxidant imbalance in smokers and chronic obstructive pulmonary disease. Thorax 1996; 51: 348-350.

18. Little P, Barnett J, Margetts B, et al. The validity of dietary assessment in general practice. $J$ Epidemiol Community Health 1998; 53: 165-172.

19. Bingham SA, Gill C, Welch A, et al. Comparison of dietary assessment methods in nutritional epidemiology: weighed records versus $24 \mathrm{~h}$ recalls, foodfrequency questionnaires and estimated-diet records. Br J Nutrition 1994; 72: 619-643.

20. Ferris B. Epidemiology standardization project. Am Rev Respir Dis 1978; 118: 1-120.

21. Hurd S. The impact of COPD on lung health worldwide. Chest 2000; 117: 1s-4s.

22. Margetts B, Nelson M. Design Concepts in Nutritional Epidemiology. Oxford, Oxford University Press, 1997.

23. Schwartz J, Weiss ST. Relationship between dietary vitamin $\mathrm{C}$ intake and pulmonary function in the First National Health and Nutrition Examination Survey (NHANES 1). Am J Clin Nutr 1994; 59: 110-114.

24. Britton JR, Pavord ID, Richards KA, et al. Dietary antioxidant vitamin intake and lung function in the general population. Am J Respir Crit Care Med 1995; 151: 1383-1387.

25. Grievink L, Smit H, Ocke M, van't Veer P, Kromhout D. Dietary intake of antioxidant (pro)-vitamins, respiratory symptoms and pulmonary function: the MORGEN study. Thorax 1998; 53: 166-171. 